\title{
Ocean Science Journal indexed in the Science Citation Index Expanded
}

\author{
Won Joon Shim* \\ Editor-in-Chief
}

South Sea Research Institute, KIOST, Geoje 656-830, Korea

(C) KSO, KIOST and Springer 2014

\section{Dear Readers and Reviewers,}

It is my great pleasure to announce that Ocean Science Journal (OSJ) has been recently selected for a coverage in the Science Citation Index Expanded ${ }^{\mathrm{TM}}$ (SCIE) and Journal Citation Reports/Science Edition (JCR) bibliographic and citation databases. Indexing of $O S J$ covers from its first issue in 2005. The journal will soon receive a Journal Citation Impact Factor. We believe the visibility, recognition and citation of papers in $O S J$ will increase by this indexing.

Until $O S J$ was indexed in SCIE, members of the $O S J$ Editorial Board devoted themselves to mold $O S J$ as a world-class scholarly journal representing Asia. They maintained fair but stringent review processes to significantly improve the quality of manuscripts. Especially, we focused on inviting outstanding manuscripts from Asian scientists with a goal to specialize in Asian regional seas research. Since 2010, OSJ marked a new era of publication by entering into a strategic partnership with Springer. This partnership enabled worldwide distribution of $O S J$.

I would like to thank everyone who contributed in so many different ways to achieve this great success. Especially, I am truly grateful to all members of the Editorial Board for their devotion, our reviewers for exerting the most powerful impact on the quality of the journal, and all authors for submitting their invaluable research outcomes to OSJ.

We believe that $O S J$ will become an essential journal for scientists in the world. We look forward to your continuous supports and contributions to $O S J$.

Warm Regards,

Won Joon Shim

Editor-in-Chief of Ocean Science Journal

*Tel: +82-55-639-8671

E-mail: wjshim@kiost.ac 